\title{
Factors Influencing Graduate Program Choice Among Undergraduate Women
}

Bryna J. Harrington

University of North Carolina at Chapel Hill, bryna_harrington@med.unc.edu

Halei C. Benefield

University of North Carolina at Chapel Hill, hcb10@med.unc.edu

Brooke C. Matson

University of North Carolina at Chapel Hill, brooke_matson@med.unc.edu

Rebecca E. Hamlin

Icahn School of Medicine at Mount Sinai, rehamlin@gmail.com

Jennifer E. L. Diaz

Icahn School of Medicine at Mount Sinai, jennifer.e.I.diaz@gmail.com

Cooper Rowan Medical Journal: https://rdw.rowan.edu/crjcsm

See next page for additional authors

Would you like to be a reviewer? Please fill in this short form to express your interest.

\section{Recommended Citation}

Harrington, Bryna J.; Benefield, Halei C.; Matson, Brooke C.; Hamlin, Rebecca E.; Diaz, Jennifer E. L.; Mosley, Grace E.; Cholera, Rushina; and Verde, Audrey R. (2019) "Factors Influencing Graduate Program Choice Among Undergraduate Women," Cooper Rowan Medical Journal: Vol. 1 : Iss. 1 , Article 5.

DOI: 10.31986/issn.2578-3343_vol1iss1.5

Available at: https://rdw.rowan.edu/crjcsm/vol1/iss1/5

\section{(c) (i)}

This work is licensed under a Creative Commons Attribution 4.0 License.

This Medical Education is brought to you for free and open access by the Rowan University Journals at Rowan Digital Works. It has been accepted for inclusion in Cooper Rowan Medical Journal by an authorized editor of Rowan Digital Works. For more information, please contact brush@rowan.edu. 


\section{Factors Influencing Graduate Program Choice Among Undergraduate Women}

\section{Cover Page Footnote}

Acknowledgments: We are appreciative of the survey participants and the pre-health advisors and listserv managers at the four participating institutions: University of North Carolina (UNC) at Chapel Hill, UNC Charlotte, North Carolina State University (NCSU), and East Carolina University (ECU). We gratefully acknowledge support and advice from the UNC MD-PhD leadership team (Dr. Toni Darville, Dr. Mohanish Deshmukh, Alison Regan and Carol Herion), as well as Dr. Valerie Parkas and Dr. Robert Fallar from the Icahn School of Medicine at Mount Sinai (ISMMS). This project was born out of enthusiasm and dedication for advancing women's careers from the student-run groups UNC Advocates for MD-PhD Women in Science (AMPWIS) and the Women in MSTP (WIMSTP) at ISMMS. Dr. Kathryn Hacker was instrumental in the initial momentum behind this work. We would also like to thank other members of WIMSTP, specifically Jessica Tan, Christie Nguyen, and Amara Plaza-Jennings for their contributions. Funding/support: This work was supported by National Institutes of Health grants T32 GM008719 (BJH, BCM, HCB, RC and ARV), T32 CA0057726 (HCB), F30 MH111370 (BJH), F30 HD085652 (BCM), F30 MH096664 (RC), and T32 GM007280 (REH, JELD, and GEM). The UNC AMPWIS provided money for the gift card incentives. Other disclosures: None. Ethical approval: The institutional review board at UNC reviewed the study and deemed it exempt from human subjects research. Disclaimer: The funding sources had no role in: the study design; the collection, analysis, and interpretation of data; the writing of the report; and the decision to submit for publication. The conclusions of the authors are not necessarily those of the National Institutes of Health. Author Contributions: All authors designed the study. BCM, BJH and HCB implemented the study and collected the data. BJH and HCB analyzed the data. All authors contributed to the drafting or revisions of the final manuscript. All authors approve the final version of the manuscript and agree to be accountable for all aspects of the work.

\section{Authors}

Bryna J. Harrington, Halei C. Benefield, Brooke C. Matson, Rebecca E. Hamlin, Jennifer E. L. Diaz, Grace E. Mosley, Rushina Cholera, and Audrey R. Verde 


\title{
Factors Influencing Graduate Program Choice Among Undergraduate Women
}

\author{
Bryna J. Harrington ${ }^{1,2 *}$, Halei C. Benefield ${ }^{1,2}$, Brooke C. Matson², Rebecca E. \\ Hamlin $^{3}$, Jennifer E.L. Diaz ${ }^{3}$, Grace E. Mosley ${ }^{3}$, Rushina Cholera ${ }^{4,2}$ \& Audrey R. \\ Verde $^{2,5}$ \\ ${ }^{1}$ Department of Epidemiology, University of North Carolina at Chapel Hill, Chapel Hill, NC \\ ${ }^{2}$ Medical Scientist Training Program, University of North Carolina at Chapel Hill, Chapel Hill, NC \\ ${ }^{3}$ Medical Scientist Training Program, Icahn School of Medicine at Mount Sinai, New York, NY \\ ${ }^{4}$ Department of Pediatrics, University of North Carolina at Chapel Hill, Chapel Hill, NC \\ ${ }^{5}$ Radiology, Stanford, Stanford, CA \\ *Corresponding author: bryna_harrington@med.unc.edu (Bryna J. Harrington)
}

\begin{abstract}
Context: Despite equal enrollment proportions in $\mathrm{MD}$ and $\mathrm{PhD}$ programs, there are fewer women than men in $\mathrm{MD}-\mathrm{PhD}$ programs and academic medicine. Factors important in degree program selection, including the perception of gender disparities, among undergraduate students were characterized.

Methods: In 2017, women pre-health students at four public North Carolina universities were invited to participate in an online survey regarding career plans, decision factors, and perceptions of gender disparities in $\mathrm{MD}, \mathrm{PhD}$ and $\mathrm{MD}-\mathrm{PhD}$ pathways. This study characterizes factors important to program selection, and evaluates the association of intended graduate program with perceived gender disparities using Fisher's exact tests.

Results: Among the $\mathrm{n}=186$ female survey participants, most were white (54\%) and intended MD, PhD, and/or MD-PhD programs (52\%). Sixty percent had heard of MD-PhD programs, over half had no research experience, and half were considering but uncertain about pursuing a research career. The most common factors influencing degree program choice were perceived competitiveness as an applicant, desired future work environment, and desire for patient interaction. Twenty-five percent of students considering $\mathrm{MD}, \mathrm{PhD}$, and $\mathrm{MD}-\mathrm{PhD}$ programs stated that perceived gender disparities during training for those degrees will influence their choice of program, however intended degree was not statistically associated with perceived gender disparities.
\end{abstract}


Discussion: Perceived gender disparities may influence choice of graduate training program but are not among the top factors. Perceived competitiveness as an applicant is an important career consideration among undergraduate women. Strategies to increase awareness of MD-PhD programs, to encourage women to consider all training paths for which they are qualified are needed.

What is known: Though men and women are nearly equally represented in MD-only and $\mathrm{PhD}$-only programs, women are underrepresented in $\mathrm{MD}-\mathrm{PhD}$ programs, which train physician-scientists. Prior studies have shown gender is not associated with rates of attrition from $\mathrm{MD}-\mathrm{PhD}$ programs or differences in academic preparation, research interest, or research experience, suggesting enrollment differences by gender may be due to fewer women applying to $\mathrm{MD}-\mathrm{PhD}$ programs. Gender parity in the physician-scientist workforce is critical to equitably serving a diverse patient population.

What this study adds: This study is the first to examine the role of gender disparities in the career choices of undergraduate women. Given the moderate familiarity with $\mathrm{MD}-\mathrm{PhD}$ training and lack of research experience among respondents, increased awareness of MD-PhD programs and expanded research opportunities may help undergraduates make informed career choices. This may increase women MD-PhD applicants, creating a more balanced physician-scientist workforce to address the needs of patients from all backgrounds.

Keywords: Education, Graduate, Sexism, Career Choice, Biomedical Research/education, Female

\section{INTRODUCTION}

Women are underrepresented in academic medicine, particularly in high-ranking leadership positions, ${ }^{1}$ as physician-scientists, ${ }^{2}$ and in full-time clinical positions. ${ }^{3}$ The latest Physician -Scientist Workforce Report prepared by the National Institutes of Health (NIH) revealed that women represent just $22 \%$ of MD-PhD research project grant awardees. ${ }^{4}$ Factors that differentially affect the career trajectories of women and men include, but are not limited to, a stated interest in a research-based career, ${ }^{5}$ participation in domestic and parenting responsibilities, ${ }^{5}$ available opportunities for mentorship, ${ }^{7}$ financial compensation, ${ }^{8}$ grant funding, ${ }^{9}$ and career attrition. ${ }^{10}$ Gender disparities, defined here as differences in the treatment of students who identify as female and students who identify as male, are the focus of ongoing dialogues among faculty in academic medicine but are also relevant to students entering the training pipeline at the university and graduate school level s. ${ }^{11}$

Despite approximately equivalent representation of men and women in MD-only and PhD-only training programs, only $39 \%$ of students enrolled in combined MD-PhD programs in the United States in the 2017-2018 academic year are women. ${ }^{12-14}$ Among those interested or enrolled in MD-PhD programs, gender has not been associated with differences in academic preparation, interest or experience in 
research, ${ }^{15}$ or in program attrition rates. ${ }^{16}$ The proportion of women compared to men among applicants and among matriculants are similar and both below gender parity of $50 \%,{ }^{17}$ suggesting that programs have fewer women than men primarily because fewer women choose to apply to MD- PhD programs. Faculty with both MD and $\mathrm{PhD}$ training represent $45 \%$ of the NIH-funded physician-scientist workforce even though dual degree students are a small minority of students pursuing MD degrees. ${ }^{18}$ Equalizing the gender balance in MD-PhD training programs and ultimately, in the physician-scientist workforce is a priority for the future ${ }^{11,19}$ and necessitates an examination of why women are currently underrepresented in $\mathrm{MD}-\mathrm{PhD}$ programs. Goals for this study were to identify factors central to the selection of a graduate school program (MD, PhD, or MD-PhD) by women, to examine the association between perceived gender disparities and intended graduate school program, and to pinpoint opportunities for intervention that may encourage equivalent representation between men and women in MD-PhD programs. It is conceivable that the volume of discussion and media attention surrounding gender disparities in STEM fields may deter qualified candidates from applying to advanced degree programs that they would otherwise consider. Here, the authors consider the example of MD-PhD programs and hypothesize that female undergraduates' perception of gender disparities in graduate program training is negatively associated with their stated intention to matriculate to an MD-PhD program.

\section{METHODS}

\section{Survey instrument}

The 40-item survey was developed to assess the demographics, post-undergraduate training plans, and factors influencing choice of graduate program among undergraduate students (Appendix 1). Respondents who indicated interest in applying to $\mathrm{MD}, \mathrm{PhD}$, and/ or $\mathrm{MD}-\mathrm{PhD}$ programs were asked questions about who discouraged or encouraged them to apply to the indicated program $\mathrm{s}$ and about factors impacting selection of programs and institutions. Some questions were adapted from the Summer Undergraduate Research Program at Icahn School of Medicine at Mount Sinai survey (2015).

All respondents who indicated interest in graduate training answered questions about their perception of gender disparities in $\mathrm{MD}, \mathrm{PhD}$, and $\mathrm{MD}-\mathrm{PhD}$ training. "Gender disparities" were defined in the survey as “differences in the treatment of students who identify as female and students who identify as male." More specifically, specific aspects of training that may be differentially experienced by students who identify as female (e.g., differential treatment by faculty or peers, acceptance of having children, impact of length of training on family planning) were queried. Respondents were asked to rate their agreement with the statement "Gender disparities during training will play NO role in my decision about the type of degree-granting program(s) to which I will apply” with response options of true, false, or I don't know. 
All respondents were asked demographic information, including whether they identified as an underrepresented minority, which institution they attend(ed ), current year of study, and familiarity with $\mathrm{MD}-\mathrm{PhD}$ programs. "Underrepresented minority" was defined using the American Association of Medical Colleges definition: "racial and ethnic populations that are underrepresented in the medical profession relative to their numbers in the general population." Participants who indicated interest in MD, $\mathrm{PhD}$, and/or MD-PhD programs were asked which program they would select if they had to pick one today; this single choice is referred to as the "intended" training program.

\section{Survey distribution}

The survey was hosted electronically via Qualtrics at UNC-Chapel Hill. Survey invitations were emailed to undergraduate listservs for students interested in health-related careers at UNC-Chapel Hill (UNC-CH; 4,000 subscribers), East Carolina University (ECU; 4,998), North Carolina State University (NCSU; 1,427), and UNC-Charlotte (UNC-C; 2150). Responses were not linked to the participant's name or other identifying information. Participants could enter their email address in a separate, unlinked survey for a chance to win a $\$ 10$ Amazon gift card. The survey remained open for a minimum of two weeks at each institution.

\section{Statistical analysis}

All data were analyzed in SAS 9.4 (SAS Institute, Cary, North Carolina). Total respondents included participants who completed every page of the survey without missing demographic responses.

Demographic data were summed and reported as percentages of total respondents. Due to a low number of men respondents, analyses feature only women respondents. Chi square tests $(\alpha=0.05)$ were used for two sets of categorical variables to evaluate the association of current institution with familiarity with MD-PhD programs, and of interest in a career in research with research experience. Factors influencing choice of graduate program and institution were reported as distributions across all women respondents and by type of program in which the respondent indicated interest. Participants could indicate interest in multiple programs and select all factors that apply, or write-in other factors.

Among participants interested in $\mathrm{MD}, \mathrm{PhD}$, and/or MD-PhD programs, using Fisher' s exact tests, the associations of intended degree program with the following were examined: perceived gender disparities in training programs and career success of $\mathrm{MD}, \mathrm{PhD}$, and $\mathrm{MD}-\mathrm{PhDs}$; and stated role of gender disparities in graduate program decision. Six questions about gender disparities in training and in success of MD, $\mathrm{PhD}$ and MD-PhDs were originally on a 5-point Likert scale ranging from "strongly disagree" to "strongly agree", with an additional option "I don't know." Response patterns for "neutral" and "I don't know" were examined via Fisher's exact tests and were not meaningfully different, so they were grouped into one option (“neutral/I don't know”) in analyses. "I don’t know” comprised approximately half of this group 


\section{RESULTS}

In November 2017, a total of 186 women completed the survey. Responses were comparable between R1 (highest research activity) and R2/R3(higher or moderate research activity) universities (1.4\% and $1.8 \%$ of listserv subscribers, respectively). Most participants were white (5 $4 \%), 41 \%$ identified as an underrepresented minority (Table 1). Most participants (92\%) were currently completing their undergraduate degrees. Overall, $52 \%$ of participants were considering $\mathrm{MD}, \mathrm{PhD}$, and/or MD-PhD training. When asked to pick one program, most intended to pursue MD degrees (77\%), followed by MD-PhD $(15 \%)$ or $\mathrm{PhD}(8 \%)$ degrees (data not shown).

Table 1 Characteristics of female undergraduate student respondents in North Carolina in 2017

\begin{tabular}{ll}
\hline Total & 186 \\
Age (median, IQR) & $20(19,21)$ \\
Ethnicity & N $(\%)$ \\
White & $101(54)$ \\
Black, African, AA & $26(14)$ \\
Hispanic or Latino & $16(9)$ \\
Asian or Pacific Islander & $21(11)$ \\
Multiple/Other/Do not wish to answer & $22(12)$ \\
Underrepresented minority & \\
Yes & $76(41)$ \\
No & $109(59)$ \\
Major & \\
Biological sciences & $113(61)$ \\
Public Health & $19(10)$ \\
Physical sciences and engineering & $14(8)$ \\
Psychology or Sociology & $15(8)$ \\
Other & $25(13)$ \\
Year in School & \\
Undergrad 1 & $38(20)$ \\
Undergrad 2 & $53(28)$ \\
Undergrad 3 & $41(22)$ \\
Undergrad 4 & $39(21)$ \\
Recent Graduate & $11(6)$ \\
Other & $4(2)$ \\
Programs considering & \\
MD, PhD, and/or MD-PhD & $96(52)$ \\
Other professional degree & $48(26)$ \\
Master's program & $27(15)$ \\
Undecided/multiple & $15(8)$ \\
\hline &
\end{tabular}

Sixty percent of women indicated familiarity with MD-PhD training (Figure 1). However, familiarity 
varied significantly by institution: students attending universities classified as R2 or R3 (ECU and UNC-Charlotte) were less familiar with MD-PhD training than students at R1 institutions (UNC-Chapel Hill and NCSU). About half of respondents $(n=98,53 \%)$ stated they were unsure of their interest in a career that involves research, and over half had no prior research experience $(n=101,54 \%)$. Overall, interest in a research career varied by experience with research $(\mathrm{p}=0.01)$, with lack of research experience most prevalent among those unsure of their interest in a research career (Figure 2).

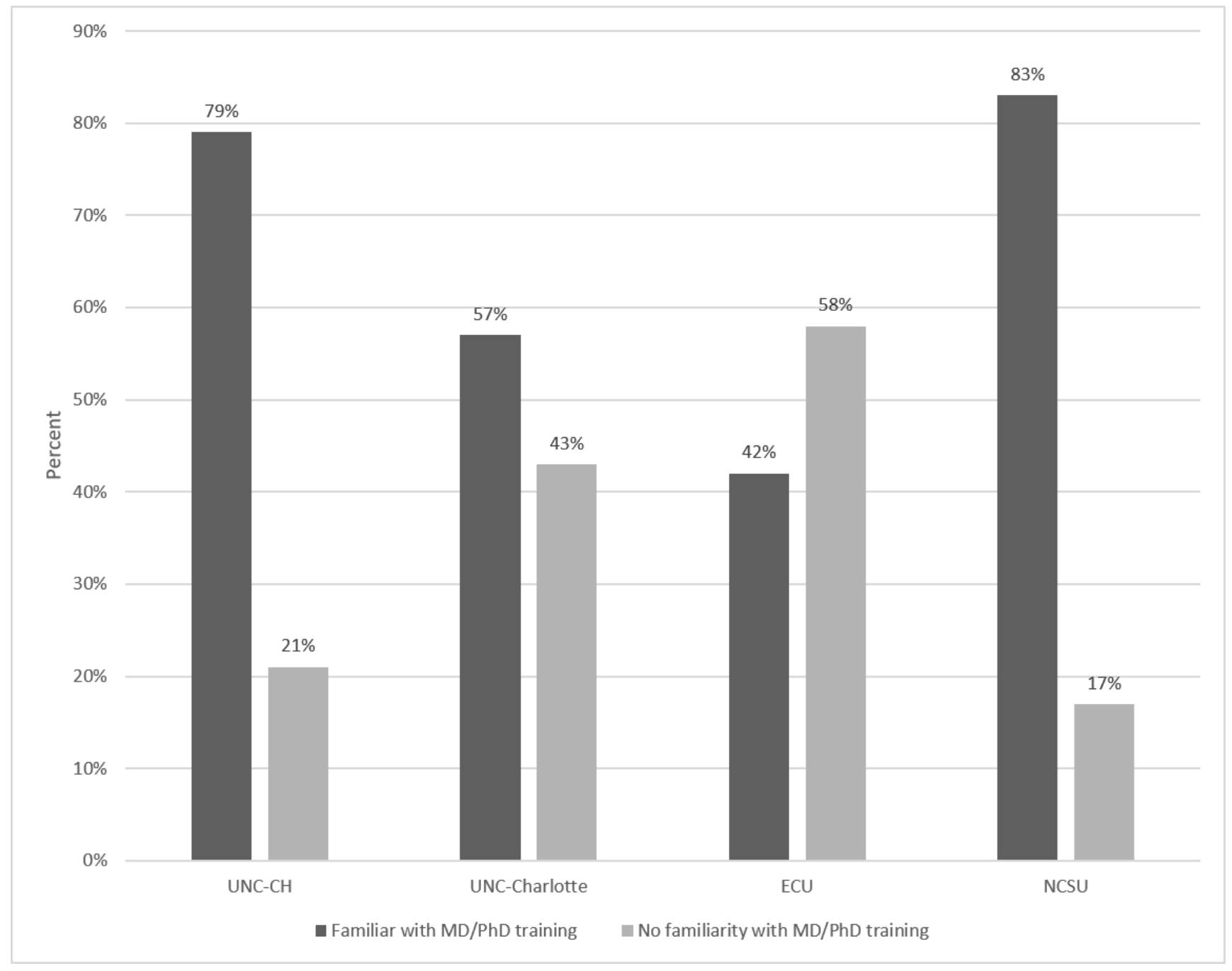

Figure 1 Familiarity with $\mathrm{MD} / \mathrm{PhD}$ training program by institution. Proportion of respondents familiar was statistically significantly different by institution ( $\mathrm{p}$-value $<0.0001$ ). 


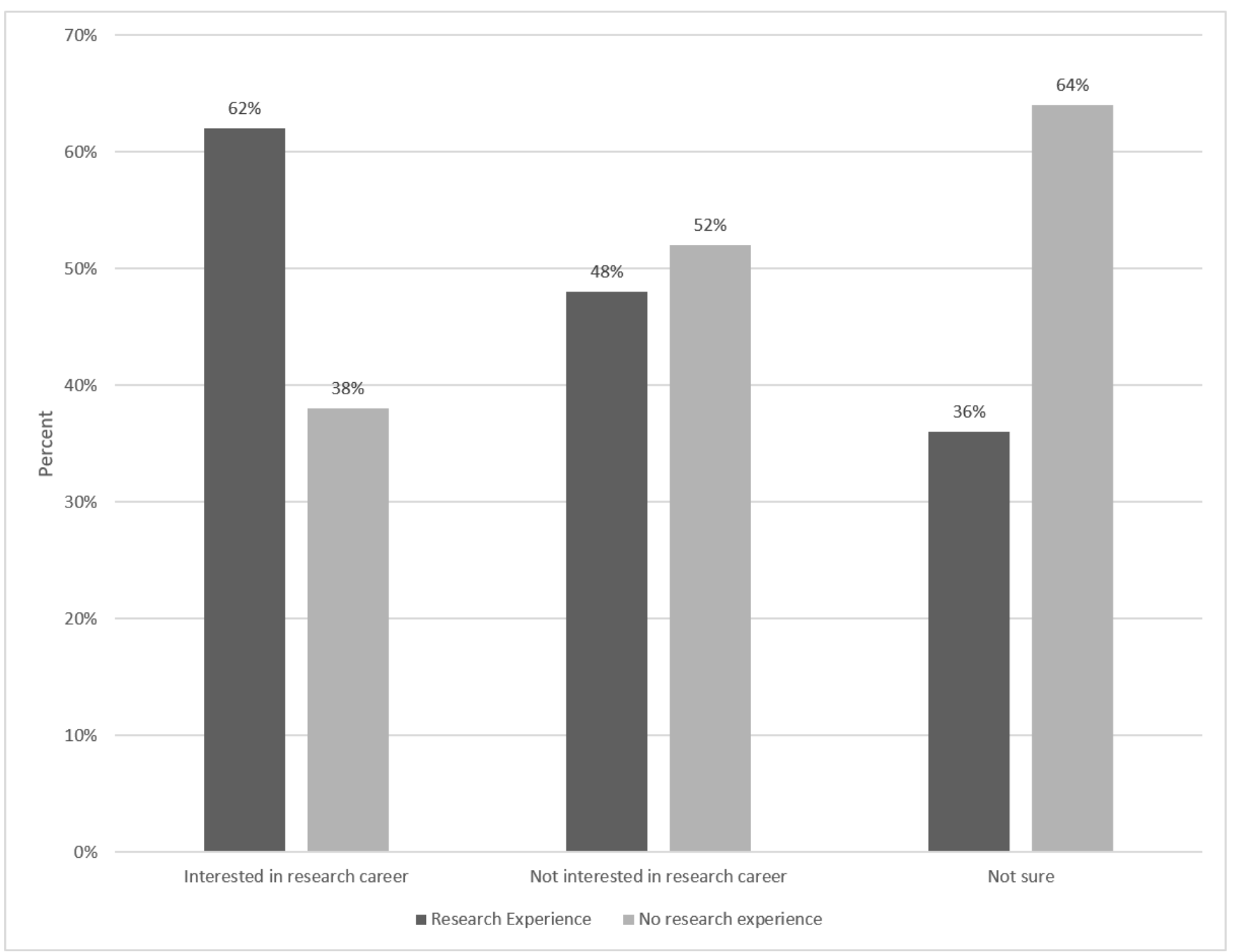

Figure 2 Percentage of respondents with research experience by interest in research career. Proportion of students with research experience was statistically significantly different by interest in research career $(\mathrm{p}$-value $=0.01)$.

Among women interested in $\mathrm{MD}, \mathrm{PhD}$, and/or MD-PhD training ( $\mathrm{n}=96$ ), the top seven factors cited when selecting which degree-granting program to apply were : perceived competitiveness as an applicant (76\%), desired future work environment (71\%),desire for patient interaction (52\%), funding during program/personal finances (50\%), prestige of program (47\%), length of training (46\%), and perceived workload/stress during training (45\%) (Table 2). Some women (15\%) ranked gender barriers to success in career as a factor that influences their selection of a graduate program. When selecting an institution for training, the five most important considerations listed were location (58\%), program funding (50\%), prestige of institution (48\%), perceived competitiveness as an applicant (33\%), feeling of "fit" with current students (33\%). 
Table 2 Factors central to selection of academic training program and institutions among female undergraduate students in North Carolina in 2017 considering MD, $\mathrm{PhD}$, and/or MD-PhD programs

\begin{tabular}{|c|c|}
\hline \multicolumn{2}{|l|}{$\begin{array}{l}\text { Factors endorsed when selecting to which PROGRAM } \\
\text { to apply a (\% total) }\end{array}$} \\
\hline 1. Perceived competitiveness as an applicant & $76 \%$ \\
\hline 2. Desired future work environment & $71 \%$ \\
\hline 3. Desire for patient interaction & $52 \%$ \\
\hline 4. Funding during program/personal finances & $50 \%$ \\
\hline 5. Prestige of program & $47 \%$ \\
\hline 6. Length of training & $46 \%$ \\
\hline 7. Perceived workload/stress during training & $45 \%$ \\
\hline 8. Ability to balance life with training & $40 \%$ \\
\hline 9. Income potential following training & $38 \%$ \\
\hline 10. Role models & $34 \%$ \\
\hline 11. Timeline for impact on society & $31 \%$ \\
\hline 12. Gender barriers to success in career & $15 \%$ \\
\hline 13. Emphasis on research & $14 \%$ \\
\hline 14. Employment situation of spouse/partner & $8 \%$ \\
\hline 15. Childcare resources during training & $4 \%$ \\
\hline \multicolumn{2}{|l|}{$\begin{array}{l}\text { Factors endorsed when selecting to which INSTITU- } \\
\text { TIONS to apply }{ }^{a}(\% \text { total })\end{array}$} \\
\hline 1. Location & $58 \%$ \\
\hline 2. Program funding & $50 \%$ \\
\hline 3. Prestige of institution & $48 \%$ \\
\hline 4. Perceived competitiveness as an applicant & $33 \%$ \\
\hline 5. Feeling of " fit" with current students & $33 \%$ \\
\hline 6. Size of program & $22 \%$ \\
\hline 7. Friendliness of administration/program directors & $20 \%$ \\
\hline 8. Proximity to family & $15 \%$ \\
\hline 9. Representation of students of same ethnicity & $8 \%$ \\
\hline 10. Representation of students of other ethnicities & $6 \%$ \\
\hline 11. Acceptance of having children during training & $3 \%$ \\
\hline 12. Employment situation of spouse/partner & $2 \%$ \\
\hline 13. Resources for childcare & $2 \%$ \\
\hline 14. Representation of students of same gender & $1 \%$ \\
\hline 14. Representation of students of other genders & $1 \%$ \\
\hline
\end{tabular}

${ }^{a}$ Respondents could select all options that apply

There were no statistically significant differences in the selection of intended degree program across any gender disparity questions (Table 3). Collectively between all those intending an $\mathrm{MD}, \mathrm{PhD}$, or MD-PhD program, about half of participants agreed that there were gender barriers in training (range 43-60\%) and to career success (range $42-53 \%$ ) as an $\mathrm{MD}, \mathrm{PhD}$, or $\mathrm{MD}-\mathrm{PhD}$. While not significant, slightly more $\mathrm{MD}$ intending participants agreed that gender disparities exist in MD training (64\%) and career success (57\%) than in training and success as a $\mathrm{PhD}(53 \%$ and $43 \%$, respectively) or as an $\mathrm{MD}-\mathrm{PhD}(42 \%$ and $39 \%$, respectively). Among participants intending to pursue an $\mathrm{MD}$ or a $\mathrm{PhD}$ program, the majority of women 
(64\% and 63\%, respectively) agreed that there are gender disparities in their intended programs' training process, whereas a lower proportion of students intending an MD-PhD program endorsed "agree" (43\%) that there are disparities in $\mathrm{MD}-\mathrm{PhD}$ training, however, $43 \%$ of those intending an $\mathrm{MD}-\mathrm{PhD}$ program answered "neutral/I don't know". Among students intending an MD-PhD program, about half agreed that gender disparities exist in training for an $\mathrm{MD}-\mathrm{PhD}(43 \%), \mathrm{PhD}(50 \%)$, and $\mathrm{MD}(50 \%)$. Students intending an $\mathrm{MD}-\mathrm{PhD}$ agreed more often to the presence of gender disparities in the success of an MD-PhD career (5 0\%) compared to in a career as a PhD (36\%) or an MD (4 $3 \%)$. When explicitly asked, $57 \%$ of women said disparities would play no role in their choice of program, while $25 \%$ said disparities would play a role, and $18 \%$ were not sure (Table 3). Those intending MD training more frequently indicated that gender disparities would play no role in their choice of program compared to those intending a PhD or an MD-PhD (MD: 61\%, PhD: 38\%, MD-PhD: 50\%) (Table 3). Uncertainty regarding whether gender disparities would influence their degree program decision was highest among those intending a $\mathrm{PhD}(50 \%)$, compared with only $14 \%$ of those intending an $\mathrm{MD}$ and $21 \%$ of those intending an MD-PhD. However, none of the differences reached statistical significance.

(Page Break for Table 3 on the following page.) 
Table 3 Distribution of perceived gender disparities among female undergraduates in North Carolina in 2017 by intended degree program

\section{There are gender disparities:}

In the MD training process

Agree

Disagree

Neutral/I don't know

In the PhD training process

Agree

Disagree

Neutral/I don't know

In the MD-PhD training process

Agree

Disagree

Neutral/I don't know

That affect my ability to succeed as an MD

Agree

Disagree

Neutral/I don't know

That affect my ability to succeed as a PhD

Agree

Disagree

Neutral/I don't know

That affect my ability to succeed as an

MD-PhD

Agree

Disagree

Neutral/I don't know

\section{Intended degree program \\ $\mathbf{M D}^{a} \quad \mathbf{P h D}^{a} \quad \mathbf{M D}-\mathbf{P h D}$ \\ $\% \quad \% \quad \%$}

$\begin{array}{ll}\text { All } & \text { P- } \\ \text { degrees \% } & \text { value } \\ b\end{array}$

0.74

$\begin{array}{llll}64 & 50 & 50 & 60 \\ 12 & 13 & 14 & 13 \\ 24 & 38 & 36 & 27\end{array}$

$\begin{array}{llll}53 & 63 & 50 & 53\end{array}$

$\begin{array}{llll}5 & 13 & 21 & 8\end{array}$

$\begin{array}{llll}42 & 25 & 29 & 39\end{array}$

$\begin{array}{llll}42 & 50 & 43 & 43\end{array}$

$\begin{array}{llll}4 & 13 & 14 & 6\end{array}$

$\begin{array}{llll}54 & 38 & 43 & 51\end{array}$

$\begin{array}{llll}57 & 38 & 43 & 53\end{array}$

$\begin{array}{llll}24 & 25 & 36 & 26\end{array}$

$\begin{array}{llll}19 & 38 & 21 & 21\end{array}$

$\begin{array}{llll}43 & 38 & 36 & 42\end{array}$

$\begin{array}{llll}19 & 25 & 29 & 21\end{array}$

$\begin{array}{llll}38 & 38 & 36 & 37\end{array}$

0.39

$\begin{array}{llll}39 & 50 & 50 & 42 \\ 16 & 25 & 29 & 19 \\ 45 & 25 & 21 & 40\end{array}$

Gender disparities will play NO role in my

choice of program

True

$\begin{array}{llll}61 & 38 & 50 & 57\end{array}$

False

$26 \quad 13$

29

57

I don't know

$14 \quad 50$

21

18

$a$ Respondents who indicated if they had to choose one program today, they would choose $\mathrm{MD}, \mathrm{PhD}$, or MD-PhD training $b$ Determined using Fisher' $s$ exact test with significance at alpha $=0.05$

\section{DISCUSSION}

In this population of women undergraduates at large, public universities in North Carolina, perceived gender disparities were not significantly associated with intended graduate degree. Women most commonly cited perceived competitiveness as an applicant and desired work environment as important to selecting a graduate degree program. Awareness of $\mathrm{MD}-\mathrm{PhD}$ programs varied significantly by institution research intensity; overall $60 \%$ of respondents indicated familiarity with this training pathway. 
The working hypothesis was that women undergraduates' perception of gender disparities in graduate program training is negatively associated with stated intention to matriculate to an $\mathrm{MD}-\mathrm{PhD}$ program. Encouragingly, none of the gender disparity responses were significantly associated with intended degree program. However, multiple data points in this study's results suggest gender disparities are a concern for some aspiring biomedical professionals. When asked explicitly whether gender disparities would play a role in the participant's choice of degree program, $25 \%$ of those intending to pursue an $\mathrm{MD}, \mathrm{PhD}$ or $\mathrm{MD}$ $\mathrm{PhD}$ said disparities would influence their decision. Ideally, perceived gender disparities would never play a role in womens' career decisions. Initiatives that facilitate undergraduate research experiences and help students learn about careers in research, such as integrated summer programs ${ }^{23}$ or course-based undergraduate research experiences (CURES), ${ }^{24-26}$ may help eliminate the effect of perceived gender disparities in graduate training choices. It is important not only that these initiatives exist, but that they promote a culture that welcomes and values women, supports women as they make career decisions, and provide encounters with mentors that are supportive and relatable ${ }^{27}$. Such initiatives and culture changes may strengthen the scientific identities and motivation of early undergraduate women, and could also serve to increase interest in MD-PhD training among women. ${ }^{28}$

Over three-quarters of female participants considering $\mathrm{MD}, \mathrm{PhD}$, and/or $\mathrm{MD}-\mathrm{PhD}$ programs stated that their perceived competitiveness as an applicant was a determining factor in their choice of graduate degree program. Women consistently underrate their competence, even at an early age. ${ }^{20,21}$ While not unique to MD-PhD training, women who consider MD-PhD training as the best way to achieve their career goals may inappropriately self-select out of the applicant pool because they perceive that they are underqualified to apply. Because attitudes and perceptions are internalized at an early age, it would be beneficial for all women — and especially those attracted to hyper-competitive careers and environments like academic medicine - to be able to accurately assess their competencies and apply with confidence to programs that match those qualifications. In addition to perceived competitiveness, other highly ranked factors concerned the nature of the work itself (work environment and patient interaction) and burden of training (financial support, stress, and duration of training). Encouragingly, these factors were endorsed more often than other reasons commonly thought to account for the gender disparity, including the desire for work-life balance, perceived gender barriers to success, and role models. ${ }^{11}$ It is likely that experience s that allow women to assess their competencies and qualifications (i.e. undergraduate research initiatives, faculty mentorship) will also help them learn about the day-to-day mechanics and training pathways of different research careers.

Familiarity with MD-PhD training programs was lowest among students at R2 or R3 universities without affiliated $\mathrm{MD}-\mathrm{PhD}$ programs. It is likely that awareness of $\mathrm{MD}-\mathrm{PhD}$ programs and the physician-scientist career path is even lower in the general student population compared to this study's sample of pre-health 
listserv subscribers, $60 \%$ of whom indicated knowledge of the joint degree pathway. Additionally, about half of the "neutral/I don't know" responses in the questions about gender disparities in training and success for $\mathrm{PhD}$ and $\mathrm{MD}-\mathrm{PhD}$ careers were originally coded as "I don't know" and were from students who intended to pursue an MD, which indicates that many aspiring physicians are not sure about the presence or effect of gender disparities in more research-oriented training programs and careers. The data from the current study indicate an opportunity for an intervention to disseminate information about $\mathrm{MD}-\mathrm{PhD}$ programs to both the student population as well as undergraduate research and pre-health advisers. Students at universities without MD-PhD programs may benefit from stronger collaborations between the MD-PhD program and undergraduates, or on-campus information sessions co-hosted by MD-PhD trainees at neighboring institutions. ${ }^{\mathrm{s}}$ Furthermore, mentoring support from faculty members has been shown to strengthen the scientific identities and motivation of early undergraduate women, and a limitation of this study is that the authors do not know to which program students will ultimately apply, and their responses reflect their perceptions, rather than empirical experiences, with graduate programs.

Participants' hypothetical choice one degree program at the time of the survey approximates their future path, but their decision may change over time. Strengths of this study include the participation of students from multiple universities as well as those who identified as underrepresented minorities.

In summary, undergraduate women's perceptions of gender disparities in $\mathrm{MD}, \mathrm{PhD}$, and $\mathrm{MD}-\mathrm{PhD}$ training programs; factors that influence their choice of degree program; and sources of encouragement or discouragement to pursue specific paths are presented. In the current study, one in four students intending to pursue an $\mathrm{MD}, \mathrm{PhD}$, or $\mathrm{MD}-\mathrm{PhD}$ program stated that gender disparities during training will influence their choice of program. The most commonly cited factor influencing choice of degree program was perceived competitiveness as an applicant - a factor that women consistently underrate. Finally, self-rated understanding of $\mathrm{MD}-\mathrm{PhD}$ programs varied significantly by institutional research intensity, and very few students were encouraged by pre-health advisers to pursue $\mathrm{MD}-\mathrm{PhD}$ training. Altogether, there is room for increased dissemination of information about $\mathrm{MD}-\mathrm{PhD}$ programs to both undergraduate students and pre-health advisers. Future research should evaluate whether such initiatives generate earlier interest in physician-scientist training and encourage women to apply for and remain in physicianscientist careers. 


\section{REFERENCES}

1. Carr PL, Raj A, Kaplan SE, Terrin N, Breeze JL, Freund KM. Gender Differences in Academic Medicine: Retention, Rank, and Leadership Comparisons From the National Faculty Survey. Acad Med 2018.

2. Ley TJ, Rosenberg LE. The physician-scientist career pipeline in 2005: build it, and they will come. JAMA 2005; 294(11): 1343-51.

3. Darbar M, Emans SJ, Harris ZL, Brown NJ, Scott TA, Cooper WO. Part-time physician faculty in a pediatrics department: a study of equity in compensation and academic advancement. Acad Med 2011; 86(8): 968-73.

4. National Institutes of Health. NIH Physician-scientist Workforce (PSW) Working Group Report 2014. http://acd.od.nih.gov/reports/PSW_Report_ACD_06042014.pdf Accessed October 2018.

5. Guelich JM, Singer BH, Castro MC, Rosenberg LE. A gender gap in the next generation of physician-scientists: medical student interest and participation in research. J Investig Med 2002; 50(6): 412-8.

6. Jolly S, Griffith KA, DeCastro R, Stewart A, Ubel P, Jagsi R. Gender differences in time spent on parenting and domestic responsibilities by high-achieving young physician-researchers. Ann Intern Med 2014; 160(5): 344-53.

7. Kong X, Chakraverty D, Jeffe DB, Andriole DA, Wathington HD, Tai RH. How Do Interaction Experiences Influence Doctoral Students' Academic Pursuits in Biomedical Research? Bull Sci Technol Soc 2013; 33(3-4): 76-84.

8. Ash AS, Carr PL, Goldstein R, Friedman RH. Compensation and advancement of women in academic medicine: is there equity? Ann Intern Med 2004; 141(3): 205-12. 
9. Jeffe DB, Andriole DA. Prevalence and predictors of US medical graduates' federal F32, mentoredK, and R01 awards: a national cohort study. J Investig Med 2018; 66(2): 340-50.

10. Ley TJ, Hamilton BH. Sociology. The gender gap in NIH grant applications. Science 2008; 322(5907): 1472-4.

11. Andrews NC. The other physician-scientist problem: where have all the young girls gone? Nat Med 2002; 8(5): 439-41.

12. AAMC. Table A-1: U.S. Medical School Applications and Matriculants by School, State of Legal Residence, and Sex, 2017-2018. https://www.aamc.org/download/321442/data/factstablea1.pdf.

13. NSF. Table 56. Statistical profile of doctorate recipients in life sciences fields, by sex and field of study: 2016. https://www.nsf.gov/statistics/2018/nsf18304/data/tab56.pdf.

14. AAMC. Table B-11.2: Total MD-PhD Enrollment by U.S. Medical School and Sex, 2013-2014 through 2017-2018. https://www.aamc.org/download/321554/data/factstableb11-2.pdf.

15. Jeffe DB, Andriole DA, Wathington HD, Tai RH. The emerging physician-scientist workforce: demographic, experiential, and attitudinal predictors of MD-PhD program enrollment. Acad Med 2014; 89(10): 1398-407.

16. Jeffe DB, Andriole DA, Wathington HD, Tai RH. Educational outcomes for students enrolled in MD-PhD programs at medical school matriculation, 1995-2000: a national cohort study. Acad Med 2014; 89(1): 84-93.

17. AAMC. Table B-8: U.S. Medical School MD-PhD Applications and Matriculants by School, InState Status, and Sex, 2017-2018. https://www.aamc.org/download/321544/data/factstableb8.pdf.

18. NIH. Appendix IV: Physician-scientists Workforce Data Chapter 2 Main Data. https://www.report.nih.gov/Workforce/PSW/chapter_2_main_data.aspx. 
19. Harding CV, Akabas MH, Andersen OS. History and Outcomes of 50 Years of Physician-Scientist Training in Medical Scientist Training Programs. Acad Med 2017; 92(10): 1390-8.

20. Eccles JS. Gender Roles and Women's Achievement-Related Decisions. Psychol Women Q 1987; 11(2): $135-72$.

21. Dunning D. Why People Fail to Recognize Their Own Incompetence. Curr Dir Psychol Sci 2003; 12(3): 83-7.

22. Jeffe DB, Yan Y, Andriole DA. Do research activities during college, medical school, and residency mediate racial/ethnic disparities in full-time faculty appointments at U.S. Medical schools? Acad Med 2012; 87(11): 1582-93.

23. Gotian R, Raymore JC, Rhooms SK, Liberman L, Andersen OS. Gateways to the Laboratory: How an MD-PhD Program Increased the Number of Minority Physician-Scientists. Acad Med 2017; 92(5): 628-34.

24. Jansen DA, Jadack RA, Ayoola AB, et al. Embedding Research in Undergraduate Learning Opportunities. West J Nurs Res 2015; 37(10): 1340-58.

25. Bangera G, Brownell SE. Course-based undergraduate research experiences can make scientific research more inclusive. CBE Life Sci Educ 2014; 13(4): 602-6.

26. Auchincloss LC, Laursen SL, Branchaw JL, et al. Assessment of course-based undergraduate research experiences: a meeting report. CBE Life Sci Educ 2014; 13(1): 29-40.

27. Cheryan S, Ziegler SA, Montoya AK, Jiang L. Why are some STEM fields more gender balanced than others?. Psychological Bulletin. 2017 Jan;143(1):1.

28. Hernandez PR, Bloodhart B, Barnes RT, et al. Promoting professional identity, motivation, and persistence: Benefits of an informal mentoring program for female undergraduate students. PLoS One 2017; 12(11): e0187531. 
29. Morales DX, Grineski SE, Collins TW. Influences on Faculty Willingness to Mentor Undergraduate Students from Another University as Part of an Interinstitutional Research Training Program. CBE Life Sci Educ 2016; 15(3). 
Supplemental Figure 3. Sources of encouragement or discouragement among female undergraduates in North Carolina in 2017 considering MD, $\mathrm{PhD}$, and/or MD-PhD programs

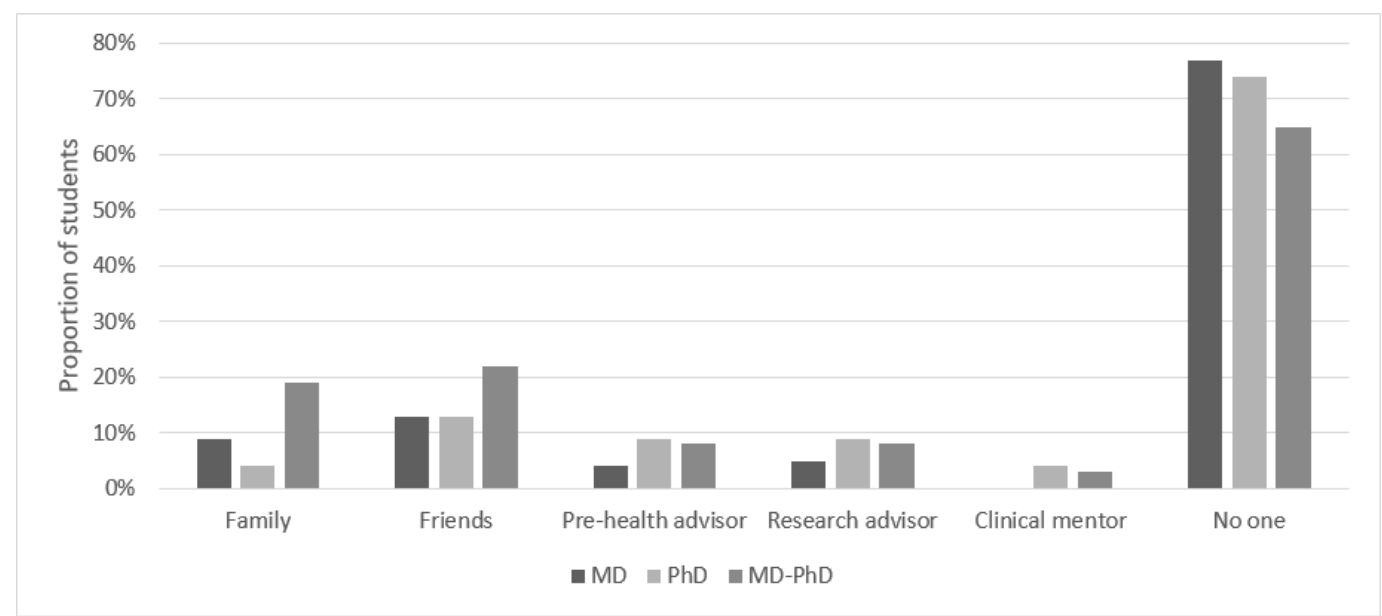

People who encouraged students to pursue a graduate training program

$80 \%$

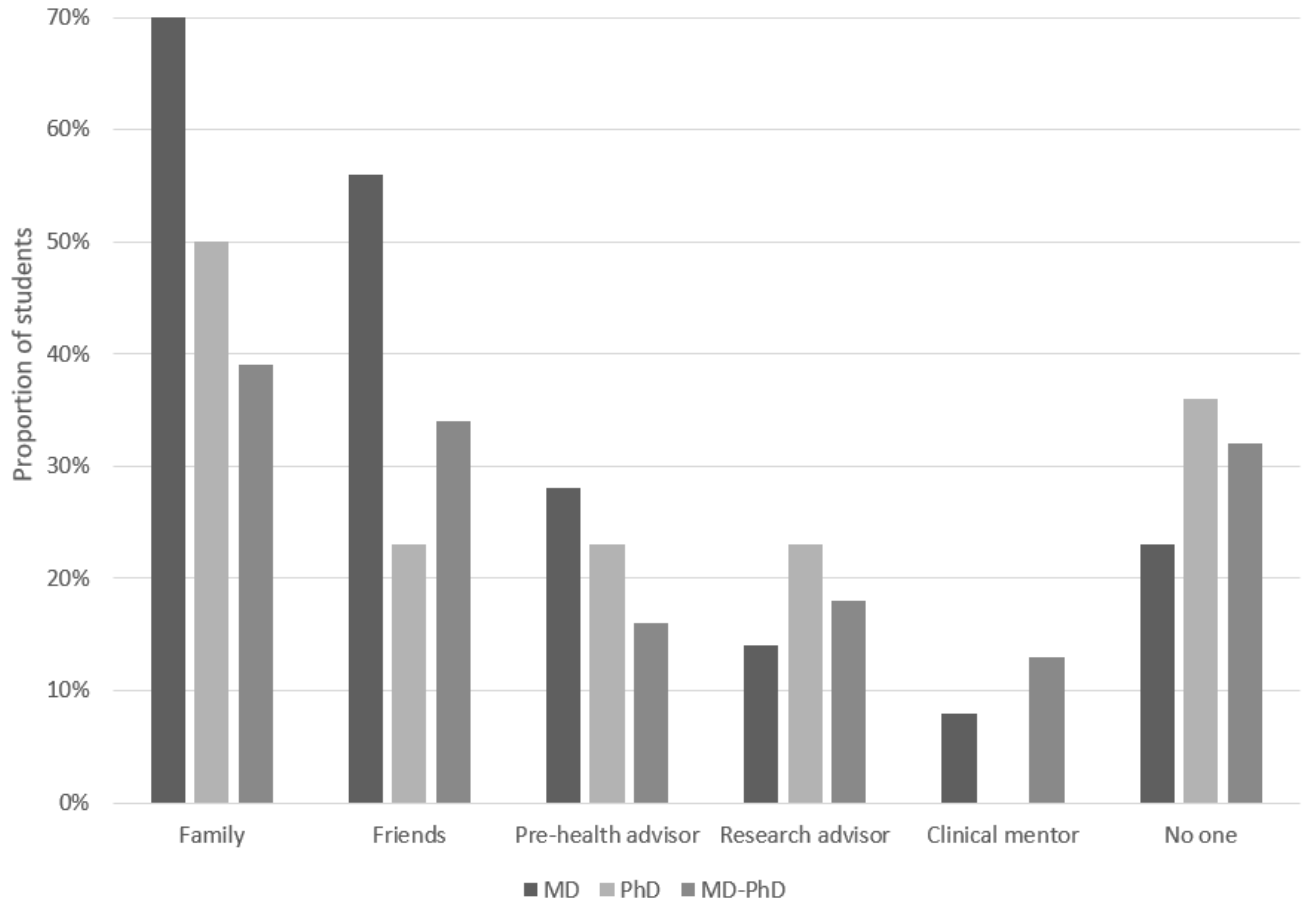

People who discouraged students from pursuing a graduate training program 